$\mathrm{pH}$ and microwave power effects on the el ectron spi $n$ resonance spectra of Rhus vernicifera I accase and Cucumis sat i vus ascor bate oxi dase

\begin{tabular}{|l|l|}
\hline 著者 & $\begin{array}{l}\text { Sakur ai Takeshi , Suzuki Shi nni chi ro, Chi ki ra } \\
\text { Nakot o }\end{array}$ \\
\hline $\begin{array}{l}\text { j our nal or } \\
\text { publ i cat i on ti tl e }\end{array}$ & Journal of Bi ochemi st ry \\
\hline vol une & 107 \\
\hline number & 1 \\
\hline page r ange & $37-42$ \\
\hline year & $1990-01-01$ \\
\hline URL & ht t p: //hdl . handl e. net /2297/16746 \\
\hline
\end{tabular}




\title{
pH and Microwave Power Effects on the Electron Spin Resonance Spectra of Rhus vernicifera Laccase and Cucumis sativus Ascorbate Oxidase $^{1}$
}

\author{
Takeshi Sakurai, ${ }^{*}$ Shinnichiro Suzuki, ${ }^{* *}$ and Makoto Chikira*** \\ "College of Liberal Arts and Sciences, Kanazawa University, Kanazawa, Ishikawa 920; "*College of General \\ Education, Osaka University, Toyonaka, Osaka 560; and "** Department of Industrial Chemistry, Faculty of Science, \\ Chuo University, Bunkyo-ku, Tokyo 112
}

Received for publication, July 13, 1989

\begin{abstract}
The present study shows that the electron spin resonance (ESR) spectral features of Rhus laccase depend considerably on the $\mathrm{pH}$ value of the enzyme solution and the irradiated microwave power. Because of the local protein structure change, the type 1 copper is appreciably autoreduced at alkaline $\mathrm{pH}$ as monitored both by the ESR'and absorption spectroscopies. In addition, the ESR signal of the type 2 copper, especially'its $g g_{\perp}$ region, becomes prominent at alkaline $\mathrm{pH}$. Protein dissociation from a water or an imidazole group coordinated to the type 2 copper is supposed to be responsible for this behavior. Besides above pH effects, the $g_{\perp}$ component of the type 2 copper ESR signal is obscured with rising microwave power level. The power saturation behavior of native laccase and its derivatives reveals that the type 2 copper is more easily saturated than the type 1 copper. Cucumis ascorbate oxidase also exhibits similar behavior upon $\mathrm{pH}$ variation and microwave power saturation.
\end{abstract}

Laccase (benzenediol: oxygen oxidoreductase) [EC 1.10.3.2], ascorbate oxidase (L-ascorbate: oxygen oxidoreductase) [EC 1.10.3.3], and ceruloplasmin ( $\mathrm{Fe}$ (II): oxygen oxidoreductase) [EC 1.16.3.1] are multicopper oxidases contain. ing three distinct types of copper centers. Type 1 copper, or so-called blue copper, exhibits an intense visible absorption at around $600 \mathrm{~nm}$, attributable to the $\mathrm{S}^{-}(\mathrm{Cys}) \rightarrow \mathrm{Cu}^{2+}$ charge transfer band, and yields an ESR spectrum with a very narrow hyperfine splitting. The ESR spectrum of the type 2 copper is characteristic of the usual tetragonal copper complex. In the visible spectrum the $d-d$ transition is observable only for the derivatives of multicopper oxidases $(1,2)$. The type 3 copper site accepts twoelectrons and functions as the binding and reaction center for $\mathrm{O}_{2}$. Type 3 coppers are ESR silent even in the oxidized form, because the two copper(II) ions are very strongly antiferromagnetically coupled. This type of copper does not contribute to the visible absorption either, but does to the shoulder at around $330 \mathrm{~nm}$. However, a highly rhombic tetragonal Cu ESR signal has been reported for a semireduced form of the type 3 copper site (3). Although laccase, ascorbate oxidase, and ceruloplasmin respectively contain 4, 8, and 5 plus some extra copper ions, it was recently established that every active site is composed of one type 1, one type 2, and two type 3 coppers (henceforth denoted by "1-1-2") (ascorbate oxidase is a dimeric enzyme containing two active sites) (4-6).

We have wondered why the hitherto reported ESR spectra of native laccase are quite diverse in spite of the fixed copper content (7-9). In addition, the ESR spectrum of zucchini (summer squash) ascorbate oxidase has been

This study was supported in part by a Grant-in-Aid ( $\$ 63540487$ ) for Scientific Research from the Ministry of Education, Science and Culture of Japan. simulated not with 2-2-4 coppers but with 3-1-4 coppers $(10,11)$. In order to solve these fundamental problems on ESR spectra we made detailed ESR studies on laccase and ascorbate oxidase in the range of $\mathrm{pH} 5.1$ to 9.5. Ceruloplasmin was excluded from the present study because of its extra type 1 copper which does not participate in the enzyme reaction $(5,6)$.

\section{MATERIALS AND METHODS}

Purification of Laccase and Ascorbate Oxidase-Laccase was prepared from Chinese lacquer latex (Rhus vernicifera) supplied by Takano and Co., Kanazawa, according to the method of Reinhammar (12). $A_{280} / A_{615}=17$ was satisfactory, ensuring the purity of the enzyme. Ascorbate oxidase was purified from cucumber peelings by the usual method (13). The final absorption ratio, $A_{280} / A_{610}$ was 24. Potassium phosphate buffer (pH 6) was used throughout the preparation and storage of both enzymes.

Preparation of Samples for Spectral Measurements - Native enzymes at different $\mathrm{pHs}$ were prepared by dialyzing the enzymes in $\mathrm{pH} 6$ buffer against an appropriate $\mathrm{pH}$ potassium phosphate or Tris-HCl buffer for 1 day. Prolonged incubation was not done to avoid fatal denaturation. The laccase derivative, in which the type 1 copper site was occupied by $\mathrm{Hg}(\mathrm{II})$, the type 2 copper site by $\mathrm{Cu}$ (II), and the type 3 copper sites by $2 \mathrm{Cu}$ (II)s [in the ESR detectable met form $\left(\mathrm{Cu}^{2+} \mathrm{Cu}^{2+}\right)$ ] or by $2 \mathrm{Co}$ (II)s, were prepared according to our previous method (2). Protein concentration was determined based on the absorbance at $280 \mathrm{~nm}$. The absorption coefficients of both enzymes did not change significantly over the $\mathrm{pH}$ range in this study. All reagent-grade chemicals were used without further purification. 
Spectral Measurements-ESR spectra at $77 \mathrm{~K}$ were measured on a JEOL JES.FE1X spectrometer and those at lower temperatures on a JEOL JES-FE2XG spectrometer. Temperatures below $77 \mathrm{~K}$ were obtained with a liquidhelium transfer system (Air Products LTD-3-110). The magnetic field was calibrated using an Echo Electronics EFM-2500 gaussmeter. The microwave frequency was calibrated on a Takedariken TR5212 microwave counter. Cu-EDTA was used to estimate the ESR signal intensities by the usual double integration method. Lithium $N, N, N^{\prime}, N^{\prime}$-tetracyanoquinodimethane (Li-TCNQ) ( $g=$ 2.0025) was used to calibrate the estimation error of the ESR signal intensities arising from the difference in tuning conditions. CD spectra were measured on a JASCO J-500A spectropolarimeter.

Computer Simulation of ESR Spectra-Computer simulations of the ESR spectra of native laccase and ascorbate oxidase were performed using a program developed by M.C. As the initial parameters for the type 1 and type 2 coppers, those of the selectively type 2 copper-depleted enzymes $(13,14)$ and those of the $\mathrm{Hg}$ (II)-substituted derivatives at the type 1 copper sites (2) were employed, respectively. Afterwards, spin Hamiltonian parameters were slightly modified during the iteration processes. The effect of $\mathrm{Cu}$ isotopes $\left({ }^{63} \mathrm{Cu}\right.$ and $\left.{ }^{65} \mathrm{Cu}\right)$ and superhyperfine splitting due to $\mathrm{N}$ donors, which are not usually taken into consideration, were also included for the simulations.

\section{RESULTS}

Effect of $p H$ on the Absorption and ESR Spectra of Laccase-ESR spectra of native laccase were measured between $\mathrm{pH} 5.1$ and 9.5 . The spectra obtained at $0.78 \mathrm{~mW}$

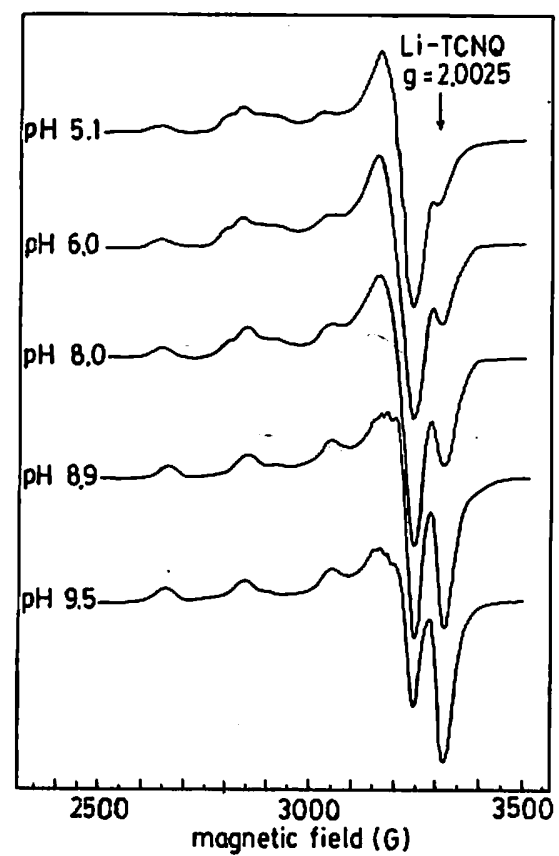

Fig. 1. ESR spectra of laccase at $77 \mathrm{~K}$ and $9.21 \mathrm{GHz}$ (ca. 0.22 $\mathrm{mM}$ protein, $0.1 \mathrm{M}$ potassium phosphate buffers at $\mathrm{pH} 5.1$ and 6.0, 0.1 M Tris-HCl buffers at pH 8.0, 8.8, and 8.5). The microwave power was $0.78 \mathrm{~mW}$, the modulation frequency was $100 \mathrm{kHz}$, and the field modulation was $8 \mathrm{G}$. are shown in Fig. 1. The reason why such a low microwave power was employed is given later. The type 2 copper signal ( $g_{/ /}=2.237, g_{\perp}=2.053, A_{\not \prime}=198 \mathrm{G}, A_{\perp}=20 \mathrm{G}$ ), especially its $g_{\perp}$ region, became conspicuous at higher $\mathrm{pH}$. The spectral features at alkaline $\mathrm{pH}(9.5)$ were rather similar to those of the Hg-substituted laccase derivative at its type 1 copper binding site $(2,15)$. On the other hand, the $g_{\perp}$ component of the type 2 copper signal became weak at lower $\mathrm{pH}$, while the type 1 copper signal $\left(g_{\not /}=2.298, g_{\perp}=\right.$ 2.055, $A_{*}=45 \mathrm{G}, A_{\perp}=20 \mathrm{G}$ ) became predominant.

The concomitant changes of the absorption maxima near $610 \mathrm{~nm}$ (blue band) are shown in Fig. 2 together with the values of the total amount of ESR-detectable $\mathrm{Cu}$ (II). The blue color due to the cupric form of the type 1 copper remained between $\mathrm{pH} 5$ to 6 , but began to fade with rising $\mathrm{pH}$. Moreover, the amount of ESR-detectable $\mathrm{Cu}$ (II) began to decrease from 2 to a lower value, indicating that significant autoreduction of the type 1 copper occurred at alkaline $\mathrm{pHs}$. The type 1 copper must not have changed to type 2 copper because the blue color and the type 1 ESR signal were restored, although not completely, by treating the laccase in a high $\mathrm{pH}$ buffer solution with a slight excess of $\mathrm{H}_{2} \mathrm{O}_{2}$ (unpublished data). The absorbance at about 610 $\mathrm{nm}$ and the total amount of the ESR-detectable $\mathrm{Cu}^{2+}$ changed in a similar manner on $\mathrm{pH}$ variation. The discrepancy between the decrease of the blue color ( $64 \%$ at $\mathrm{pH}$ 9.5) and that of the ESR-detectable $\mathrm{Cu}$ (II) (56\% at pH 9.5) may be explained by a minor change of the absorptivity of the charge transfer band $\left(\mathrm{Cys} \rightarrow \mathrm{Cu}^{2+}\right)$. A slight but prominent blue shift from 615 to $606 \mathrm{~nm}$ of the $\mathrm{Cys} \rightarrow \mathrm{Cu}^{2+}$ charge transfer band was observed in the absorption spectra as the pH was raised (Fig. 2). CD spectra $(300-800 \mathrm{~nm}$, not shown) suggested that a minor modification occurs in the protein structure at alkaline $\mathrm{pH}$. In addition, the $\mathrm{pH}$ value change on freezing may also contribute to the discrepancy described above (see "DISCUSSION").

When the $\mathrm{pH}$ values of laccase in various $\mathrm{pH}$ buffers were returned to 6 , the most frequently used $\mathrm{pH}$ for research on this enzyme, ESR spectra similar to those before $\mathrm{pH}$ changes were restored. However, since a portion of the type

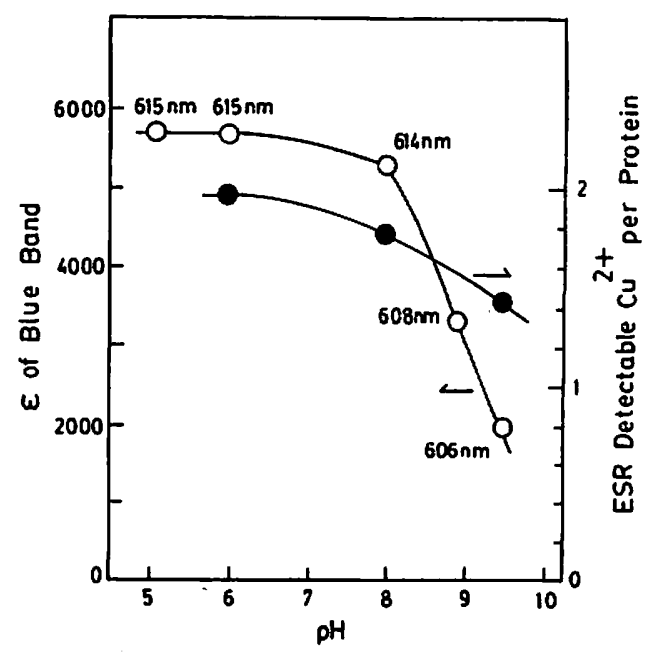

Fig. 2. The amount of ESR detectable $\mathrm{Cu}$ (II) per protein molecule and molar absorptivity of the blue band of laccase at different $\mathrm{pH}$. The values in the figure show the absorption maxima of the blue band. 
1 copper in the reduced form had been lost from protein molecule, the type 1 copper ESR signal was decreased partly (spectra not shown). In the respective absorption spectra, the absorption maximum position of the blue band returned from $608 \mathrm{~nm}$.(pH 8.9) or $606 \mathrm{~nm}(\mathrm{pH} \mathrm{9.5)}$ to 615

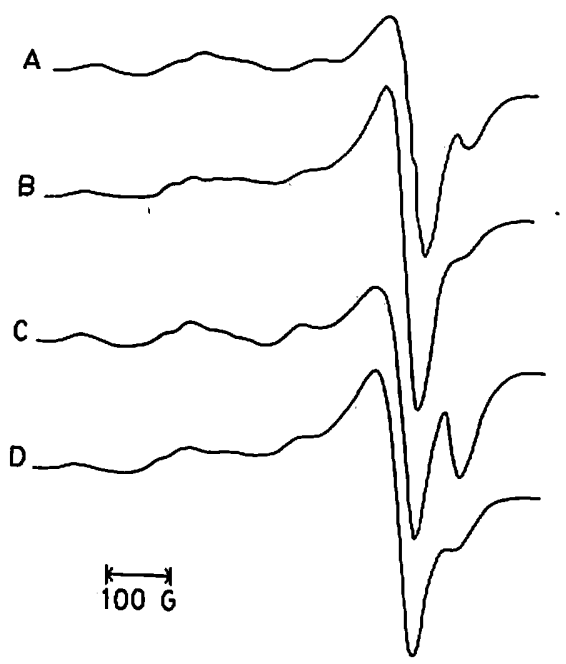

Fig. 3. ESR spectra of laccase (ca. $0.2 \mathrm{mM}$ ) at $77 \mathrm{~K}$ (A: pH 6.0, $0.025 \mathrm{~mW}$; B: pH 6.0, $200 \mathrm{~mW}$; C: pH 8.0, $0.05 \mathrm{~mW}$; D: pH 8.0, $200 \mathrm{~mW}$ ). The microwave frequency was $9.24 \mathrm{GHz}$, the modulation frequency was $100 \mathrm{kHz}$, and the modulation amplitude was $8 \mathrm{G}$.

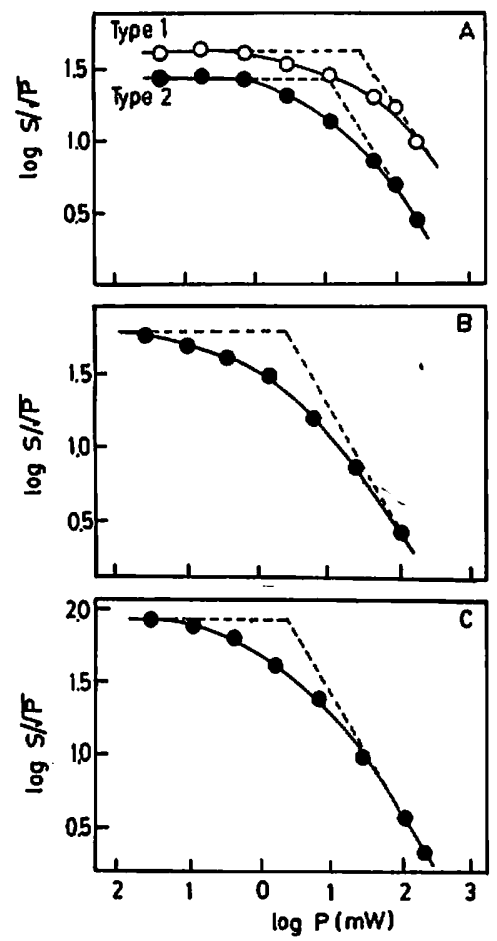

Fig. 4. Power saturation curves of the native laccase (A), T1HgT2CuT3Cu (ESR-detectable met form) laccase (B), and T1HgT2CuT3Co laccase (C) at $10 \mathrm{~K}$. The concentration of each sample was ca. $0.2 \mathrm{mM}$ per protein molecule, and the $\mathrm{pH}$ was 8.0 . The intersection of the asymptotic slopes at lower and higher power defines the half power saturation. $S$ and $P$ denote signal intensity and microwave power ( $\mathrm{mW}$ ), respectively. $\mathrm{nm}$. The absorption intensities also appreciably recovered.

Power Saturation Behavior of Laccase-Saturation of a paramagnetic system with incident microwave power has been widely applied in ESR studies to elucidate both electronic and structural properties of spin systems (16). However, the technique has never been applied to laccase, although the ESR spectra of the enzyme have been repeatedly measured. We investigated the ESR spectra of laccase in several buffers with the irradiation of different microwave power levels at 10,60 , and $77 \mathrm{~K}$. Generally, the saturation of paramagnetic species occurs easily at low

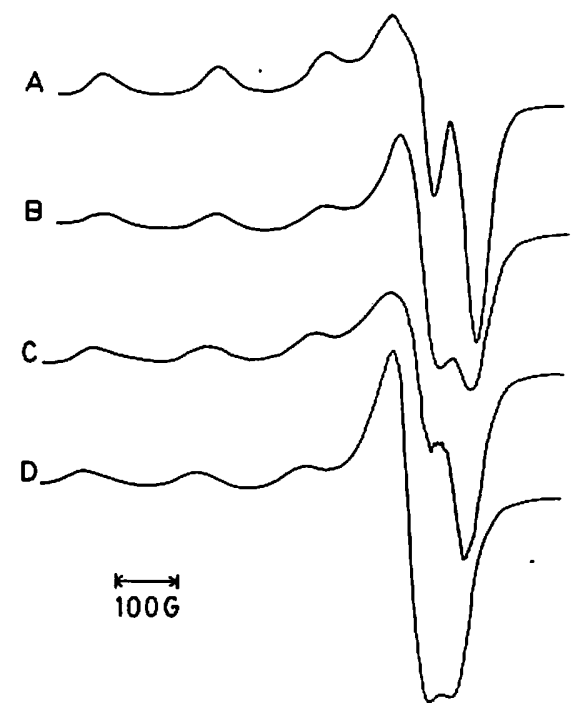

Fig. 5. ESR spectra of laccase derivatives measured at $10 \mathrm{~K}$ with low and high microwave powers (A: T1HgT2CuT3Co, $0.025 \mathrm{~mW}$; B: T1HgT2CuT3Co, $200 \mathrm{~mW}$; C: T1HgT2CuT3Cu, $0.025 \mathrm{~mW}$; D: T1HgT2CuT3Cu, $200 \mathrm{~mW}$ ). The other conditions for measurements were similar to those shown in Fig. 4.

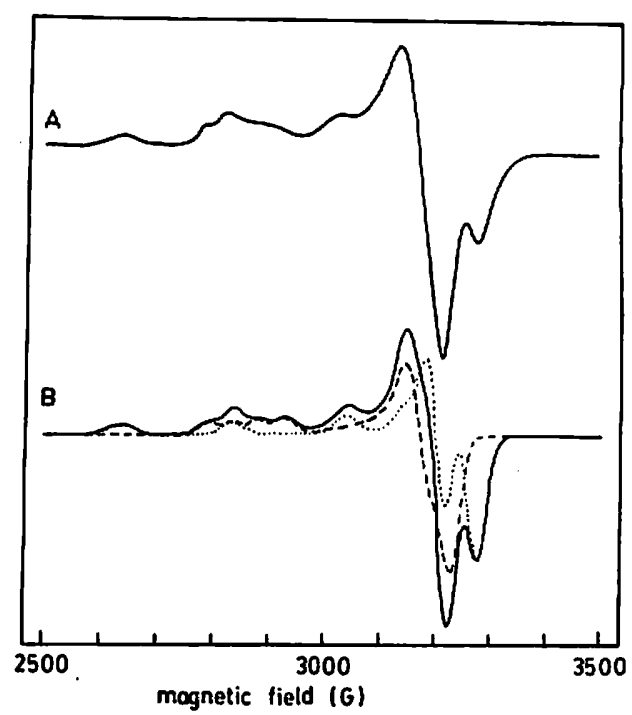

Fig. 6. Experimental (A) and simulated (one type $1 \mathrm{Cu}$ and one type $2 \mathrm{Cu}$ ) (B) ESR spectra of laccase at $8.21 \mathrm{GHz}$ and $77 \mathrm{~K}$. The broken and dotted lines represent the type 2 copper $\left(g_{\|}=2.237, g_{\perp}=\right.$ 2.053, $\left.A_{A \prime}=198 \mathrm{G}, A_{\perp}=20 \mathrm{G}\right)$ and the type 1 copper $\left(g_{\not h}=2.298\right.$, $g_{\perp}=2.055, A_{/ /}=45 \mathrm{G}, A_{\perp}=20 \mathrm{G}$ ), respectively. 


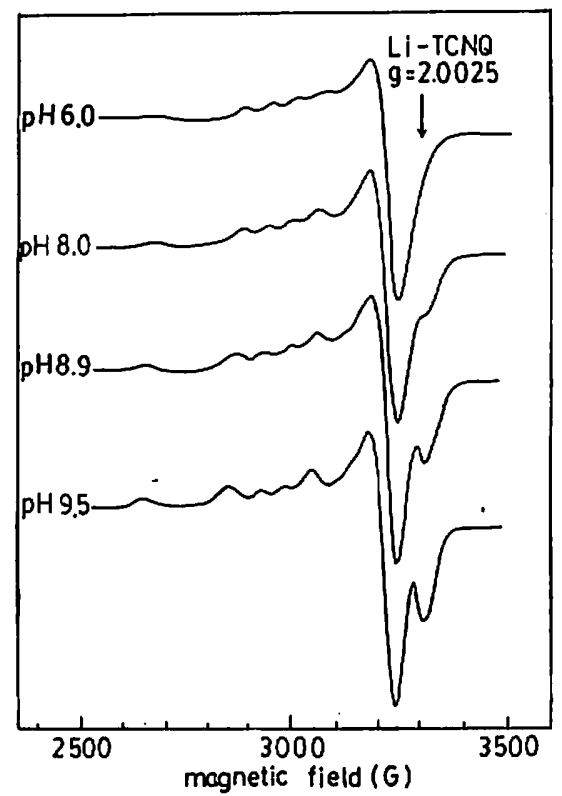

Fig. 7. ESR spectra of ascorbate oxidase (ca. $0.03 \mathrm{mM}$ ) at $77 \mathrm{~K}$ in different $\mathrm{pH}$ buffers [pH 6.0 (potassium phosphate buffer) and pH 8.0, 8.9, and 8.5 (Tris-HCl buffer)]. The microwave power was $3 \mathrm{~mW}$, the microwave frequency was $9.20 \mathrm{GHz}$, the modulation frequency was $100 \mathrm{kHz}$ and the modulation amplitude was $8.0 \mathrm{G}$.

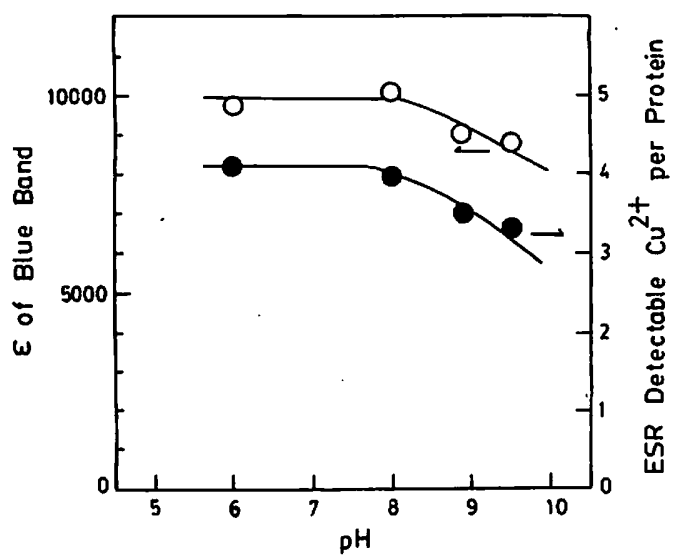

Fig. 8. The amount of ESR-detectable $\mathrm{Cu}$ (II) and the molar absorptivity of ascorbate oxidase at different pHs.

temperature near $4 \mathrm{~K}$, and accordingly the saturations of both the type 1 and type 2 coppers became more prominent at $10 \mathrm{~K}$ than at higher temperatures. ESR spectra of laccase at $\mathrm{pH} 6$ and $\mathrm{pH} 8$ measured at very low and high microwave power levels are-illustrated in Fig. 3. Now the diversity of the laccase ESR spectra reported hitherto is found to come from the differences in the irradiated microwave power and in the $\mathrm{pH}$ of the buffer solution. Saturation behavior at $\mathrm{pH}$ 8 and $10 \mathrm{~K}$ is shown in Fig. 4A. Since the signal shape of the type 2 copper, especially its $g_{\perp}$ region, varies considerably at a high microwave power, signal intensity was followed at the $g_{H}$ region $(2,946 \mathrm{G}$ for the type 1 copper, $2,684 \mathrm{G}$ for the type 2 copper). The ESR signal of the type 2 copper in laccase was saturated at a lower microwave power than that of the type 1 copper. The half power saturation $\left(P_{1 / 2}\right)$ for the type 1 and type 2 coppers were 15 and $4 \mathrm{~mW}$ at $10 \mathrm{~K}$ and $\mathrm{pH} 6.0$, respectively. The difference of the environment

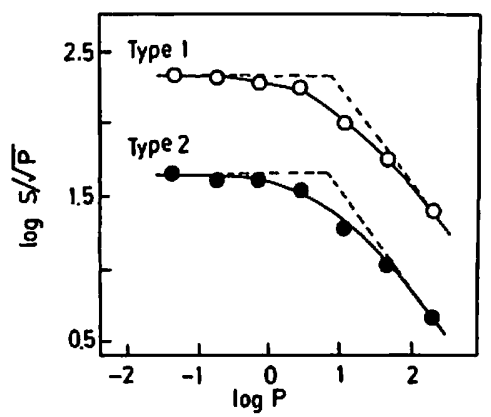

Fig. 9. The power saturation curves of the type 1 and type 2 coppers of ascorbate oxidase (pH 6.0) at $10 \mathrm{~K}$.

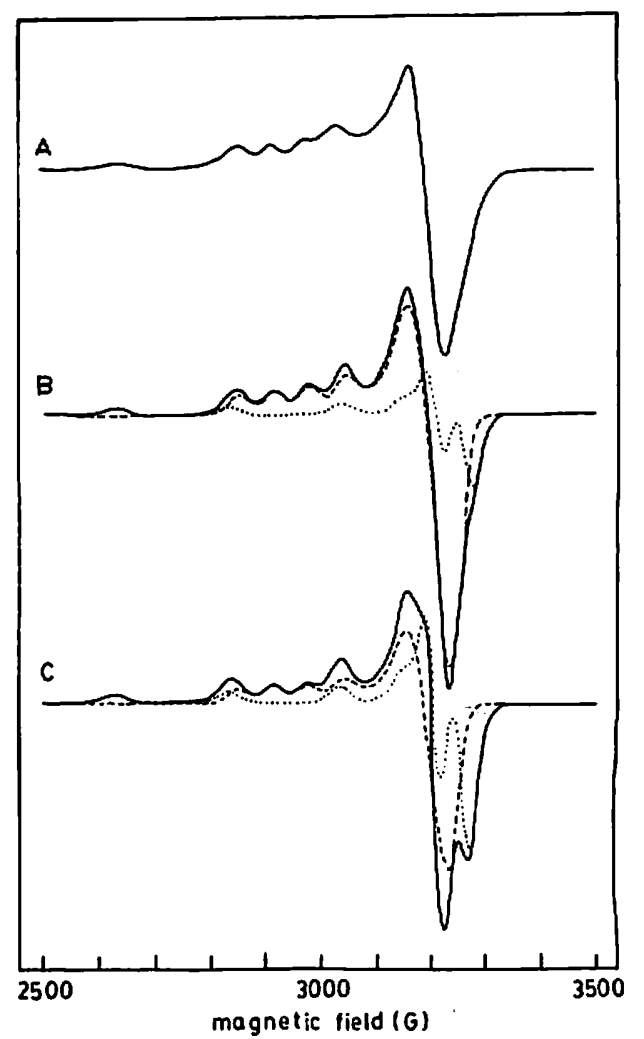

Fig. 10. Experimental (A) and simulated (B for three type 1 coppers and one type 2 copper, $C$ for two type 1 coppers and two type 2 coppers) spectra of ascorbate oxidase at $9.21 \mathrm{GHz}$ and 77 K. Spin Hamiltonian parameters for the type 2 copper are $g_{A}=2.240$, $g_{\perp}=2.050, A_{y}=198 \mathrm{G}, A_{\perp}=20 \mathrm{G}$ and those for the type 1 copper are $g_{A}=2.230, g_{\perp}=2.050, A_{A \prime}=62 \mathrm{G}, A_{\perp}=18 \mathrm{G}$.

around each type of copper site will dominate the difference of the saturation behavior. ESR spectra of two laccase derivatives, whose type 1 copper site was substituted by $\mathrm{Hg}$ (II) and the type 3 copper sites by $2 \mathrm{Co}$ (II) or $2 \mathrm{Cu}$ (II) are shown in Fig. 5. In the latter derivative, the 2 coppers incorporated into the type 3 copper sites were fully ESR detectable, affording an ESR signal very similar to that of the type 2 copper (2). These type 3 coppers in the ESRdetectable met form $\left(\mathrm{Cu}^{2+} \mathrm{Cu}^{2+}\right)$ were saturated $\left(P_{1 / 2}=2\right.$ $\mathrm{mW}$ ) somewhat more easily than the type 2 copper in the native enzyme $\left(P_{1 / 2}=4 \mathrm{~mW}\right)$ (Fig. $4, \mathrm{~A}, \mathrm{~B}$, and C).

Simulation of Laccase ESR Spectra-The results of our 
computer simulation of the laccase ESR spectrum at $\mathrm{pH} 6$ are presented in Fig. 6.

Effect of $p H$ on the Absorption and ESR Spectra of Ascorbate Oxidase-ESR spectra of ascorbate oxidase at different pHs are shown in Fig. 7. The total number of ESR-detectable $\mathrm{Cu}^{2+} \mathrm{s}$ was $4(50 \%$ of total $\mathrm{Cu})$ per protein molecule at $\mathrm{pH} 6$. With increasing $\mathrm{pH}$ value, the type 2 copper gradually became prominent, as in the case of laccase (see Fig. 1). Quantitative evaluations of the amount of ESR detectable $\mathrm{Cu}$ (II) and the absorbance of the blue band due to the type 1 copper (Fig. 8) indicate that autoreduction of the type 1 coppers occurs, although the extent is not as marked as in laccase.

Power Saturation Behavior of Ascorbate Oxidase-The power saturation behavior of ascorbate oxidase is shown in Fig. 9. The signal intensities of the type 1 and type 2 coppers were followed for the $g$, components at 2,970 and $2,640 \mathrm{G}$, respectively. The reason why the perpendicular components was not followed was to avoid the signal shape change displayed in laccase (Fig. 3). The half saturation powers of both types of copper are about $10 \mathrm{~mW}$ at $10 \mathrm{~K}$.

Simulation of ESR Spectrum of Ascorbate Oxidase -Figure 10 illustrates the simulated ESR spectra of ascorbate oxidase. Recently, the numbers of type 1 and type 2 coppers in ascorbate oxidase have both been estab. lished to be 2 (4). However, as reported in the simulation study for squash ascorbate oxidase (11), the present cucumber ascorbate oxidase, whose type 1 coppers were not autoreduced, could be better simulated as 3 type 1 coppers and 1 type 2 copper.

\section{DISCUSSION}

The $\mathrm{pH}$ change of several buffer solutions on freezing has been pointed out by Orii and Morita (17). It is ideal to observe the ESR spectra as well as the absorption spectra at room temperature; however, the measurements were performed below $77 \mathrm{~K}$ because ESR sensitivity is significantly lowered at room temperature. The effect of freezing does not seem to be serious because the pH dependences of the absorption and ESR spectra correlated fairly well.

The profound effect of $\mathrm{pH}$ on the absorption, CD and ESR spectra has been overlooked or ignored. Most studies on Rhis laccase have been performed at $\mathrm{pH} 6.0,7.0$, and 7.4. The ESR spectrum at $\mathrm{pH}>8$ is available only in the early study by Malmström et al. (pH 10.3) (18). They reported that the ESR parameters of the type 1 copper were simply modified. But we repeatedly observed that the type 1 copper is autoreduced as the $\mathrm{pH}$ of the buffer solutions increases (Figs. 1 and 2). Of the blue copper proteins containing only type 1 copper, plastocyanin has been reported to autoreduce at $\mathrm{pH} 10.2$ in parallel with the exposure of a hydrophobic site to the solvent (19). In contrast, $\mathrm{Cu}$ (II) of stellacyanin, which is contained in the latex of lacquer tree, was bound to the polypeptide chain at an extremely high $\mathrm{pH}$, giving a complex similar to $\mathrm{Cu}$ (II). biuret (20). Umecyanin has been reported to alter its color almost reversibly, when the $\mathrm{pH}$ is extremely high (21). The absorption and ESR spectra of plantacyanin (22) and a stellacyanin-like protein from spinach (23) have also been reported to change at high $\mathrm{pH}$. After all, many blue copper proteins not including plastocyanin, do not prefer the reduced form in alkaline $\mathrm{pH}$ buffers in spite of their positive redox potentials $(+180-+370 \mathrm{mV})$. Since the type 1 copper of laccase, whose redox potential is $+470 \mathrm{mV}$ at pH ca. 4 and $+380 \mathrm{mV}$ at $\mathrm{pH} c a .9(24)$, is closely related to other types of coppers (25), a geometrical change leading to autoreduction may occur without difficulty.

The only computer simulation of a laccase ESR spectrum, whose procedure was well documented, was for the spectrum obtained at $\mathrm{pH} 7.5(8)$. In the spectrum the type 2 copper signal is quite conspicuous, because the type 1 copper had been partly reduced. On the other hand, the quantitative studies by the conventional double integration method have often reached the conclusion that the type 1 and type 2 coppers of laccase are almost fully ESR detectable within the experimental error $(14,18,20,26,27)$. The same conclusion was also obtained by the present study for laccase at $\mathrm{pH} 6$. A fairly good computer simulation of the ESR spectrum at $\mathrm{pH} 6$ could be realized by reducing the type 2 copper content from 1 to a lower value (data not shown). However, it is inconsistent with the fact that the type 2 copper is almost fully ESR detectable. The question may therefore be raised whether the total amount of the ESR detectable $\mathrm{Cu}$ (II) had been overestimated. The use of an ESR signal exhibiting a different shape as a standard should be avoided if possible, since it is difficult to retain an identical tuning condition for samples to give a different dielectric loss. The power saturation behavior of $\mathrm{Cu}$-EDTA (data not shown) ensured, however, that at least saturation is not fatal when less than $5 \mathrm{~mW}$ is used for the measurements at $77 \mathrm{~K}$. Figure 6 is the final simulated spectrum in which the contributions from ${ }^{63} \mathrm{Cu}$ and ${ }^{65} \mathrm{Cu}$ and the superhyperfine splitting due to the imidazole $\mathrm{N}$ ligands were included for equal content of type 1 and type 2 coppers.

The peculiar sharpening of the perpendicular region of the type 2 copper at alkaline $\mathrm{pH}$ (Fig. 1) seems to arise from structural changes about this copper. One possibility is deprotonation from the water molecule(s) coordinated to the type 2 copper. The coordination of one or two water molecules has been established through anion binding studies $(28,29)$. The $\mathrm{p} K_{\mathrm{a}}$ values associated with a water molecule and a protein hydroxyl group coordinated to the type 2 copper of laccase have been estimated to be 6.2 and 8.6, respectively (30). Deprotonation from the coordinated imidazole group of a histidine residue is another possibility.

The case of ascorbate oxidase is very similar. As the $\mathrm{pH}$ value of the buffer solution increases, autoreduction of the type 1 copper occurs, although its extent is not so large as that of laccase. The rigidity of the local protein structure will determine the sensitivity of type 1 copper to high $\mathrm{pH}$. The reversible fading of the blue color of ascorbate oxidase at $\mathrm{pH}$ as high as 10.5 was only described in a review (31): no original data has been furnished hitherto. The numbers of type 1 and type 2 coppers of ascorbate oxidase have both been revealed to be two (4), although three type 1 coppers and one type 2 copper were favorable for the computer simulation (Fig. 10). If the computer simulation reached a satisfactory solution for two type 1 coppers and 0.7 type 2 copper (3:1 ratio) (this happens when a portion of the type 2 copper is in the reduced form), the total amount of the ESR-detectable $\mathrm{Cu}$ (II) should not have been 4 but 2.7. However, the value estimated by the conventional method using $\mathrm{Cu}$-EDTA was very near to 4, as shown in Fig. 8. It is not certain at present whether the estimation error of the 
ESR-detectable amount of $\mathrm{Cu}$ (II) or the limitation of the computer simulation is dominant.

The deprotonation process from the water molecule coordinated to the type 2 copper of ascorbate oxidase may be involved in the peculiar sharpening of the perpendicular region of the type 2 copper signal at alkaline pH (Fig. 7). Moreover, the possible deprotonation from the coordinated imidazole group (s) or the shape change of the type 2 copper ESR signal can not be excluded at present.

In Nakamura's pioneering work (7), the ESR spectrum of native laccase lacking the type 2 copper signal was reported. Further, chicken ceruloplasmin isolated promptly by a single-step chromatography did not give the type 2 copper ESR signal (32). However, X-ray crystallography of ascorbate oxidase from zucchini by Messerschmidt et al. (33), indicated that type 2 copper is the intrinsic cofactor for multicopper oxidases. A portion of the type 2 copper must be in the cuprous form, occasionally leading to its ESR signal being missing or very limited in the resting multicop. per oxidases. Otherwise, it is also plausible that the signal which has been believed to be the type 2 copper is that of the type 3 copper in the ESR-detectable met form. In any case, special attention should be paid in obtaining ESR spectrum, as the present study shows.

The type 2 copper has been supposed to be involved in the $\mathrm{O}_{2}$ reduction process (34-36). If the dissociation of the proton from the water molecule coordinated to the type 2 copper is concerned with the present ESR signal modification, it may be supposed not the type 2 copper itself but the coordinated water operates to weaken the $-0.0^{-}$bond through a hydrogen bond and/or to supply $\mathrm{H}^{+}$to the intermediate(s).

In conclusion, the results described herein from the ESR, absorption and CD spectra of laccase and ascorbate oxidase gave significant information about the $\mathrm{pH}$ effects leading to the partial autoreduction of the type 1 copper. The profound effect of the microwave power level on the ESR spectra of laccase and ascorbate oxidase was also investigated.

Thanks are due to the Instrument Center, the Institute for Molecular Science, for assistance in obtaining the ESR spectra below $77 \mathrm{~K}$.

\section{REFERENCES}

1. Dooley, D., Rawlings, J., Dawson, J.H., Stephens, P.J., Andreasson, L.-E., Malmström, B.G., \& Gray, H.B. (1979) J. Am. Chem: Soc. 101, 5038-5046

2. Sakurai, T., Suzuki, S., \& Tanabe, Y. (1989) Inorg. Chim. Acta 157, $117-120$

3. Reinhammar, B., Malkin, R., Jensen, P., Karlsson, B., Andreasson, L.-E., Aasa, R., Vănggård, T., \& Malmström, B.G. (1980) J. Biol. Chem. 255, 5000-5003

4. Morpurgo, L., Savini, I., Gatti, G., Bolognesi, M., \& Avigliano, L.
(1988) Biochem. Biophys. Res. Commun. 152, 623-628

5. Sakurai, T. \& Nakahara, A. (1986) Inorg. Chim. Acta 123, 217 220

6. Sakurai, T. \& Nakahara, A. (1986) Bull. Chem. Soc. Jpn. 59, 3501-3504

7. Nakamura, T. (1976) in Iron and Copper Proteins (Yasunobu, K., Mower, H., \& Hayaishi, O., eds.) pp. 408-423, Plenum, New York

8. Vånggård, T. (1972) in Biological Applications of Electron Spin Resonance, pp. 411-447, Wiley-Interscience, New York

9. Ando, K. (1970) J. Biochem. 68, 501-508

10. Deinum, J. \& Reinhammar, B. (1974) FEBS Lett. 42, 241-245

11. Marchesini, A. \& Kroneck, M.H. (1979) Eur. J. Biochem. 101, 65-79

12. Reinhammar, B. (1970) Biochim. Biophys. Acta 205, 623-628

13. Sakurai, T., Sawada, S., Suzuki, S., \& Nakahara, A. (1987) Biochim. Biophys. Acta 915, 238-245

14. Morpurgo, L., Graziani, M.T., Finazzi-Agro, A., Rotilio, G., \& Mondovi, B. (1980) Biochem. J. 187, 361-366

15. Morie-Bebel, M.M., Moris, M.C., Menzie, J.L., \& McMillin, D.R. (1984) J. Am. Chem. Soc. 106, 3677-3678

16. Makinen, M.W. \& Wells, G.B. (1987) in Metal Ions in Biological Systems (Siegel, H., ed.) Vol. 22, pp. 129-205, Mercell Decker, New York

17. Orii, Y. \& Morita, M. (1977) J. Biochem. 81, 163-168

18. Malmström, B.G., Reinhammar, B., \& Vänggård, T. (1970) Biochim. Biophys. Acta 205, 48-57

19. Takabe, T., Niwa, S., \& Ishikawa, H. (1980) J. Biochem. 87, 1335-1339

20. Malmström, B.G., Reinhammar, B., \& Vänggård, T. (1968) Biochim. Biophys. Acta 156, 67-76

21. Stigbrand, T. \& Sjoholm, I. (1972) Biochim. Biophys. Acta 263, 244-257

22. Sakurai, T., Okamoto, H., Kawahara, K., \& Nakahara, A. (1982) FEBS Lett. 147, 220-224

23. Sarkissian, L. \& Nalbandyan, R.M. (1983) Biosci. Rep. 3, 915920

24. Nakamura, T. (1958) Biochim. Biophys. Acta 30, 44-52

25. Sakurai, T. \& Nakahara, A. (1986) J. Inorg. Biochem. 27, 85-93

26. Reinhammar, B. \& Oda, Y. (1979) J. Inorg. Biochem. 11, 115127

27. Morpurgo, L., Desideri, A., Rotilio, G., \& Mondovi, B. (1980) FEBS Lett. 113, 153-156

28. Holwerda, R.A. \& Gray, H.B. (1974) J. Am. Chem. Soc. 96, 6008-6022

29. Morpurgo, L., Rotilio, G., Finazzi-Agro, A., \& Mondovi, B. (1974) Biochim. Biophys. Acta 336, 324-328

30. Goldberg, M., Vuk-Pavlovic, S., \& Pecht, I. (1980) Biochemistry 19, 5181-5189

31. Finazzi-Agro, A. (1987) Life Chem. Rep. 5, 199-209

32. Calabrese, L., Carbonaro, M., \& Musci, G. (1988) J. Biol. Chem. 263, 6480-6483

33. Messerschmidt, A., Rossi, A., Ladenstein, R., Huber, R., Bolo. gnesi, M., Gatti, G., Marchesini, A., Petruzzelli, R., \& Finazzi. Agro, A. (1989) J. Mol. Biol. 206, 513-529

34. Farver, O., Goldberg, M., \& Pecht, I. (1980) Eur. J. Biochem. 104, 71-77

35. Reinhammar, B. (1985) Chem. Scripta 25, 172-176

36. Koudelka, G. \& Ettinger, M.J. (1988) J. Biol. Chem. 263, 36983705 